\title{
Helping patients to reduce tobacco consumption in oncology: a narrative review
}

\author{
Claudio Lucchiari ${ }^{1 *}$, Marianna Masiero ${ }^{2,3}$, Andrea Botturi $^{4}$ and Gabriella Pravettoni ${ }^{2,3}$
}

\begin{abstract}
The present overview focuses on evidence of smoking cessation approaches in oncology settings with the aim to provide health personnel a critical perspective on how to help their patients. This narrative review is structured in two main sections: the first one describes the psycho-cognitive variables involved in the decision to continue smoking after a cancer diagnosis and during the treatment; the second section relates methods and tools may be recommended, being evidence-based, to support smoking cessation in oncology settings. Active smoking increases not only susceptibility to common cancers in the general population, but also increases disease severity and comorbidities in cancer patients. Nowadays, scientific evidence has identified many strategies to give up smoking, but a lack of knowledge exists for treatment of nicotine dependence in the cancer population. Health personnel is often ambiguous when approaching the problem, while their contribution is essential in guiding patients towards healthier choices. We argue that smoking treatments for cancer patients deserve more attention and that clinical features, individual characteristics and needs of the patient should be assessed in order to increase the attempts success rate. Health personnel that daily work and interact with cancer patients and their caregivers have a fundamental role in the promotion of the health changing. For this reason, it is important that they have adequate knowledge and resources in order to support cancer patients to stop tobacco cigarette smoking and promoting and healthier lifestyle.
\end{abstract}

Keywords: Oncology, Cigarette smoking, Smoking cessation, Decision-making

\section{Background}

Tobacco cigarette smoking is the leading cause of preventable death in the world. In 2011 the World Health Organization (WHO) declared that smoking caused six million deaths annually, and in 2030 it will kill eight million people each year (WHO 2011).

Bio-physiological evidence suggests that smoking is the main cause of respiratory diseases (e.g. chronic obstructive pulmonary disease and pulmonary emphysema), cardiovascular events (e.g. aneurysm and stroke) and many cancers (esophagus, larynx, oral cavity, bladder, stomach, kidney, squamous cell carcinoma of the cervix; Ehlers and Bronars 2012). Statistical figures confirm that tobacco dependence causes $30 \%$ of all cancers and $80 \%$ of deaths from neck, head, and lung cancer (Morgan et al.

\footnotetext{
*Correspondence: claudio.lucchiari@unimi.it

1 Department of Philosophy, Università degli Studi di Milano, Milan, Italy Full list of author information is available at the end of the article
}

2011). Particularly, about $90 \%$ of lung cancer is assignable to tobacco cigarette smoking (Nayan et al. 2011).

Despite this evidence, many patients still smoke regularly after a diagnosis of cancer. In 2013 the American National Cancer Institute published a scientific statement on treating tobacco dependence in the cancer population. The report highlighted that $50 \%$ of individuals with cancer who smoke before diagnosis continue smoking during treatment, and that, for patients who gave up smoking, the relapse rate was very high (Toll et al. 2013). Data showed that 23-35\% of head and neck cancer patients, and $13-20 \%$ of lung cancer patients who were smoking before their diagnosis, continued to smoke after the diagnosis and during treatment itself (Nayan et al. 2011), while de Bruin-Visser et al. (2012) reported that $35-72 \%$ of head and neck cancer patients' smoke despite the diagnosis.

Also women with breast cancer are reported as continuing to smoke after the diagnosis (Land et al. 2011). In 
this study, cigarette smoking was found to be negatively correlated to treatment adherence.

Continuing to smoke after a cancer diagnosis may produce several adverse health outcomes (Cropley et al. 2008). Epidemiological research shows that tobacco cigarette smoking decreases survival time (Gritz and Demark-Wahnefried 2009), it increases the risk of second primary malignancies (Zevallos et al. 2009) and the likelihood of recurrences (Schnoll et al. 2004). For instance, smokers with Hodgkin's disease have an increased risk of a second primary lung cancer (McBride and Ostroff 2003) when compared to never-smokers under the same conditions. Also, it has been shown that tobacco use decreases survival rate after hematopoietic stem cell transplantation (Marks et al. 2009; Ehlers et al. 2011). Furthermore, cigarette smoking decreases treatment efficacy (Waller et al. 2010) and increases complications and side-effects (Schnoll et al. 2004) for many types of cancer. In this regard, clinical studies revealed that in head and neck (Blalock et al. 2011), and lung (Zhang et al. 2009) cancer patients, smoking behavior decreases the efficacy of radiotherapy, while increasing drug toxicity and sideeffects (such as impaired pulmonary function, nausea, and dry mouth) (Nayan et al. 2011). Daniel et al. (2009) showed that patients with lung cancer who did not discontinue smoking reported more pain during the disease progression than former smokers and non-smokers. Similar concerns have also been observed in patients with bladder and renal cancer (Videtic et al. 2003). Finally, smoker patients have a high risk of developing postoperative complications than do non-smoker patients, for example showing poor wound healing (Thomsen et al. 2010a, b; see Table 1).

In spite of the evidence, there is still a significant lack of smoking treatment research for oncology patients. A cancer diagnosis may provide a useful teachable moment (Gritz 1991) for quitting smoking, but this chance is frequently undervalued by the healthcare system (Weaver et al. 2012).

A number of studies reported that oncology patients actually try to give up, but they generally make their attempts without help. For example, a recent study by Vaidya et al. (2014) reported that many patients keep on smoking even after a diagnosis of lung cancer. Khullar et al. (2013) stated that patients do not receive enough support from physicians. Indeed, $50 \%$ of physicians do not regularly talk about antismoking strategies with patients. Cooley et al. (2009) have shown that despite the a broad diffusion of information about the benefits of smoking cessation after a lung cancer diagnosis, few patients actually succeed in their attempt and find little support from health personnel pre- and postsurgery. Confirming this evidence, a large online survey
Table 1 Summary of the benefits related to smoking cessation during and after cancer treatment

\begin{tabular}{l} 
Benefits of smoking cessation post-diagnosis \\
\hline Physical dimension \\
Decreasing the side-effects of the therapy \\
Increasing treatment efficacy \\
Overcoming chemo resistance \\
Improving outcome of the surgery \\
Counteracting tumor progression \\
Reducing fatigue \\
Increasing activity level \\
Reducing the likelihood of developing second primary malignancies \\
Avoiding recurrence \\
Improving survival rate \\
Psychological dimension \\
Improving cognitive process \\
Enhancing psychological well-being \\
Increasing self-esteem \\
Reducing blame (when cancer is smoking-related) \\
Supporting self-efficacy health behavior-related \\
Improving mood \\
Health behaviors \\
Supporting healthy lifestyle \\
Promoting preventive behavior \\
Enhancing general quality of life of the patients (e.g. quality of sleep)
\end{tabular}

conducted by Warren et al. (2013) in 1507 members of the International Association for the Study of Lung Cancer revealed that though most physicians believes smoking cessation to be an important issues for their patients, only $40 \%$ discuss quit options and only $39 \%$ actively support patients.

Generally, oncologists provide wide-ranging suggestions regarding smoking-related risks, but they do not give detailed information regarding available treatments, nor do they offer a support program during the whole therapeutic journey (Weaver et al. 2012). This view has been recently supported by a qualitative study conducted by Champassak et al. (2014), which showed, through a series of interview, the mismatch between the physicians' believe of the importance of smoking cessation programs and the actual behavior during visits. Indeed, physicians report a lack of confidence in their smoking cessation counseling ability. Furthermore, physicians rarely reported to use recommended strategies, even when they are acknowledged. Another particular case is that of hematologic cancers. Indeed, in a hematological oncology department for patients undergoing hematopoietic stem cell transplantation, quitting is a priority, since studies exist (Chang et al. 2004) associating smoking with worse outcomes. Despite this, Ehlers et al. (2011) showed 
that many hematologic patients continue to smoke after diagnosis. Also, authors noted the lack of studies addressing the issue of helping patients quit smoking (Ehlers and Bronars 2012), and the training of healthcare professionals in the management of the smoker patient.

Starting from this theoretical background, the main aim of this brief review is to sketch an overview of the available options to approach smoking dependence in an oncology setting. In order to achieve this goal, the paper has been structured into three conceptual sections. The first section describes the role of the psycho-cognitive processes that reinforce cigarette smoking behavior in patients with cancer. The second section discusses the cognitive-behavioral interventions and smoking cessation aids, focusing both on advantages and disadvantages, in in-patient and out-patient settings. Finally, we offer some suggestions for health professionals to overcome roadblocks and to improve the smoking cessation success rate in cancer patients.

\section{Method}

This narrative review is structured in two main sections: the first one describes the psycho-cognitive variables involved in the decision to continue smoking after a cancer diagnosis and during the treatment; the second section relates methods and tools may be recommended, being evidence-based, to support smoking cessation in oncology settings.

Searches were conducted through MEDLINE, EMBASE, PubMed, SCOPUS, PsycINFO and Google Scholar. The following keywords or combinations were used: cigarettes smoking, cancer, oncology patient, oncology setting, smoking cessation, antismoking treatment, nicotine dependence, nicotine replace treatment, varenicline, bupropion, electronic cigarettes, smoking cessation counseling.

In the first section, we considered papers from 1990 to May 2016, using previous systematic reviews, national and international reports, and empirical studies. While in the second section, we included only controlled trials studies from 1990 to May 2016.

Articles in languages other than English and letters and editorials were excluded. The initial search identified 763 articles. An initial review of the titles abstracts of these articles by 2 of the authors identified 133 articles that were potentially relevant to the current review. The abstracts of these articles were then evaluated against the inclusion criteria by the authors, resulting in 35 articles being identified as eligible for inclusion, with an additional 6 articles identified during manuscript preparation, for a total of 41 articles. This review provides a narrative synthesis of the findings from previous key reviews and empirical studies identified in the literature search.
Inclusion and exclusion criteria section 1:

We included article assessing the behavioral, psychological and cognitive characteristic of adult smokers after a diagnosis of cancer, including nicotine dependence level and motivation to quit. We also reviewed paper (review or empirical studies) that evaluated the rate of patients that continue smoking after a cancer diagnosis. We excluded editorial, opinion papers, letters and articles related to adult smokers after childhood cancer.

Inclusion and exclusion criteria for section 2 :

We included prospective controlled studies about adults patients after a diagnosis of cancer during their clinical treatment, measuring the effectiveness of a smoking cessation treatment on smokers who received a diagnosis of cancer and describing the smoking cessation methods used, including the type of provider and the clinical setting. We considered studies that specify the cancer sites of patients and stage. We excluded studies on mixed population (cancer patients and other diseases), cohort studies as well as surveys.

\section{Cognitive profile of the cancer patient who smokes}

Westmaas et al. (2015), in a large prospective study on a US cohort (including more than 12,000 smokers) showed that a cancer diagnosis is associated with significantly higher rates of quitting smoking within both 2 and 4 years of the diagnosis. Almost one in three smokers who received a cancer diagnosis in their study had quit smoking within 2 years, compared with fewer than one in five smokers who had never received a cancer diagnosis. Moreover, the greater quitting rate among cancer-diagnosed smokers is maintained at 4 years. Interestingly, also non-smoking related diagnosis affected patients' smoking habits. However, even though a diagnosis of cancer seem to be a true teachable moment, not all patients actually change their behavior. In particular, patients with preexisting chronic conditions that are linked to smoking (e.g. chronic obstructive pulmonary disease) have low rates of quitting after cancer diagnosis. Coherently, Burris et al. (2015) aggregating data across 131 studies on head and neck cancer patients, found that about $50 \%$ of smokers patients continue smoking after diagnosis, while previous studies reported a range of 35-72 \% (Ostroff et al. 2013).

These data may help in describing the typical cancer patient who continue smoking after the diagnosis. Duffy et al. (2012) describe this patient as a heavy smoker (with a mean consumption of 28 cigarettes per day for 35-40 years) with a high level of nicotine addiction with a history of failed quitting attempts and some smokingrelated pathological condition. Even when these patients 
decide to attempt to stop smoking, the success rate is generally low. For instance, Walker et al. (2006) showed that lung cancer patients start smoking again only 2 months after the surgery, supporting the idea that this population is particularly challenging for smoking cessation specialists (Park et al. 2011).

Since, heavy smoking (smoking more than 20 cigarettes a day, even though different definitions are present in literature; Husten 2009) and smoking related diseases are particularly associated with lung and oral cavity cancer (Gandini et al. 2008), we may expect to find more patients who continue smoking after diagnosis in these pathological conditions. Actually, several studies of non-small-cell lung cancer patients have shown that many patients continue smoking (Gritz 1991; Dresler et al. 1996; SandersonCox et al. 2002) with estimates ranging from 13 to $70 \%$.

In particular, Walker et al. (2004) in a retrospective study of 49 lung cancer patients reported that patients who were younger and less educated were more likely to return to smoking after surgery. They also found a correlation of relapse with depression and social support. Authors suggested that patients stop smoking immediately before and after surgery, but relapse to smoking remains a problem.

Cooley et al. (2009) in a study on a sample of 94 patients with early stage non-small cells lung cancer reported similar results, but they also found a correlation between smoking and pain. Authors collected data at 1,2 and 4 months after surgery and their results suggest that the presence of pain is significantly correlated with smoking after surgery.

Schnoll et al. (2005) among 109 lung and head and neck cancer patients, showed that continued smoking after 3 months post-surgery is associated to low quitting motivation and smoking-related beliefs that increase the perception of disadvantages of quitting. In fact, in their study authors found that patients who continue smoking believe that cons of quitting are more than pros. False or biased smoking-related beliefs are frequently present in smokers. Different studies reported that smokers usually show some kind of belief bias, ranging between 20 and $80 \%$ (Masiero et al. 2015). This is also true in oncology settings. Such biased thoughts and beliefs may be exemplified by patients developing the idea that the cancer does not relate to individual choices and behavior but only to uncontrollable factors such as genetic predisposition, environmental pollution, etc. (Arnett 2000).

In particular, smokers tend to underestimate smokingrelated risks (Borrelli et al. 2010). For instance, a study of Bock et al. (2001), reported that $47.6 \%$ of smokers admitted to the emergency department for acute respiratory care did not believe that they had a condition that was caused or made worse by smoking.
Furthermore, smokers compared with non-smokers tend to underestimate risks concerning themselves, but they often change their judgment when thinking about others' risks. This attitude is defined optimistic bias (Weinstein et al. 2005; Weinstein 1989). It drives people to believe that they are protected from the consequences of potential sources of risk and reinforces cigarette smoking. However, some authors (e.g. Milbury et al. 2012; Gritz et al. 2005) have suggested that giving up smoking may be facilitated if patients become aware of the possibility of changing their behavior and in so doing reduce further risks.

Cancer-related emotional distress may favor smoking as well. Indeed, depression is often present in patients, ranging between 3 and $31 \%$ (Krebber et al. 2014). Also blame contribute to exacerbating patients' psychological distress. Paradoxically, this reaction seems to initiate a vicious circle, which reduces the motivation to start an antismoking program (e.g. Chapple et al. 2004). A study by Shin et al. (2014) on 45 patients and 173 family members who continued to smoke for at least 1 month after the diagnoses reported interesting data about the emotional experience of patients and their relatives. In this study, most smoker patients report to experience guilt toward their family (75.6 \%) and to conceal their smoking behavior. Similarly, relatives who continue smoking feel guilt toward patients (63.6 \%). Hence, both relatives and patients experience negative emotions and try to prevent conflicts hiding their behavior also to the health personnel.

Long-term abstinence can be hindered by a negative mood, since a correlation between cigarette smoking and depression is well established (McClave et al. 2009). Depressed smokers or smokers with a previous history of major depression generally have a high level of nicotine dependence and a low probability of a successfully attempt to stop smoking.

In oncology settings, depression is a critical issue for patient management. Indeed, cancer patients can experience high levels of worries, fears, anxiety and negative emotions related to the disease and its treatment (surgery, chemotherapy or radiotherapy, periodic clinical meetings, long periods of hospitalization, tests and examinations). Patients may then use cigarette smoking as a coping strategy. Furthermore, the pharmacological properties of nicotine, with its cognitive-enhancing effects, reinforces the perceived valued of cigarettes since they may be used to alleviate treatment-related negative effects on memory and attention.

Spek et al. (2013) found that the decrease of self-efficacy tends to negatively affect smokers' confidence in their ability to quit smoking. Actually, patients with a high degree of confidence in their power to give up 
smoking have a higher success rate than smokers with a low confidence. Also, they report less relapses after an attempt to quit (McBride and Ostroff 2003; Elfeddali et al. 2012).

Other context-related variables influence smoking cessation, such as living or working with people who habitually smoke. Indeed, patients who live with smokers are more likely to maintain their habit than are patients who live with non-smokers or in a smoke-free home. Furthermore, social and family support (relatives, friends, colleagues and so on) can be an important factor in promoting smoking cessation even though different studies have shown divergent results (Park et al. 2004). May and West (2000) in a review of the literature found that social support may be beneficial in helping smokers quitting, even if more research is needed to clarify the role of relatives, especially in cancer survivors. However, Schnoll et al. (2002) in a study of 74 patients found that a low readiness to quit smoking after a cancer was strongly associated with the fact of having a relative at home who smoke. After hospitalization, when the patient goes back home, smoking-related cues (e.g. a habitual smoking place; smoking-related daily routine; other people who smoke; sensorial stimuli and the like) may influence their ability to remain abstinent.

This fact has been considered as a serious barrier in helping patients to stop smoking. Indeed, daily exposure to smoking-related stimuli may produce physiological and cognitive changes that favor urgency and craving due to a so-called attentional bias. This cognitive bias is related to the selective properties of the attention. It concerns the attitude of smokers and former smokers to orient their attention to tobacco cigarette smoking cues (Field et al. 2009) favoring the need to smoke. Finally, Ark et al. (1997) found that in head and neck cancer patients heavy alcohol use is a negative predictor of smoking cessation.

\section{Smoking cessation interventions for cancer patients: state of the art}

Smoking interventions may be classified into two main approaches: smoking cessation aids (SCAs) and cognitive behavioral interventions (CBIs). Both methods are used to approach cigarette addiction in healthy adults and in cancer patients and they can be used alone or in combination. However, most research on smoking cessation has been carried out on healthy people, while there are only a few studies available on cancer patients and on survivors (Duffy et al. 2012; see Table 2).

\section{Smoking cessation aids: SCAs}

Smoking cessation aids involve three categories of antismoking strategies: nicotine replacement treatments
(NRTs), tobacco free cigarettes-(TFC) and medications (mainly bupropion and varenicline).

Nicotine replacement treatment is very popular among smokers. Generally, a first spontaneous attempt to give up involves NRT (where available without a medical prescription). They provide nicotine, stabilizing its level in the blood in order to avoid a withdrawal syndrome after having stopped smoking. They are available in different forms including transdermal nicotine replacement products, patch, gum, lozenge, inhaler, spray and sublingual tablets. Commonly, the treatment lasts for 10-12 weeks, but it is often prolonged to 6 months. The type of NRTs chosen depends on personal preference, but clinical considerations should be issued too.

Two NRT groups, depending on the administration method, are usually described. The first group includes NRTs that require daily administration, generally based on the use of patches. The second group include protocols based on multiple administrations a day, so-called short-acting NRT (Nides 2008).

The main aims of NRT are three: craving reduction, withdrawal control and abstinence promotion (Stead et al. 2008). A growing body of scientific literature stresses that NRT helps patients to give up smoking (Fiore et al. 2000). Pharmacological trials in particular have shown that the combination of multiple forms of NRT improves the interruption success rate (Ferguson et al. 2011) also in medical settings (Hurt et al. 2009). Also, NRTs have few side effects, being the most prevalent a transient nausea (Fiore et al. 2008). Their principal weak point is the low compliance, since after a short period many people interrupt the smoking cessation program, believing that they are able to control the situation without further help (Balmford et al. 2011). NRT may be successfully used with cancer patients, generally in association with some form of counseling and/or other pharmacological treatment (see Table 2). For instance, a retrospective study by Garces et al. (2004) showed that a combination of NRT and other behavioral and pharmacological treatment is as effective in head and neck cancer patients as in the general population.

A particular type of NRT involves tobacco-free cigarettes (TFCs) also called e-cigarettes. These devices have rapidly become widespread over the last 5 years, and are often used by smokers to reduce the daily number of cigarettes, or to smoke in places where tobacco cigarettes are not allowed.

A TFC device is composed of a battery-powered device that produces a vapour for inhalation. The steam contains humectants, flavours, and pure nicotine. Liquids used in e-cigarettes do not contain tobacco and do not require combustion. They may or may not contain nicotine. 


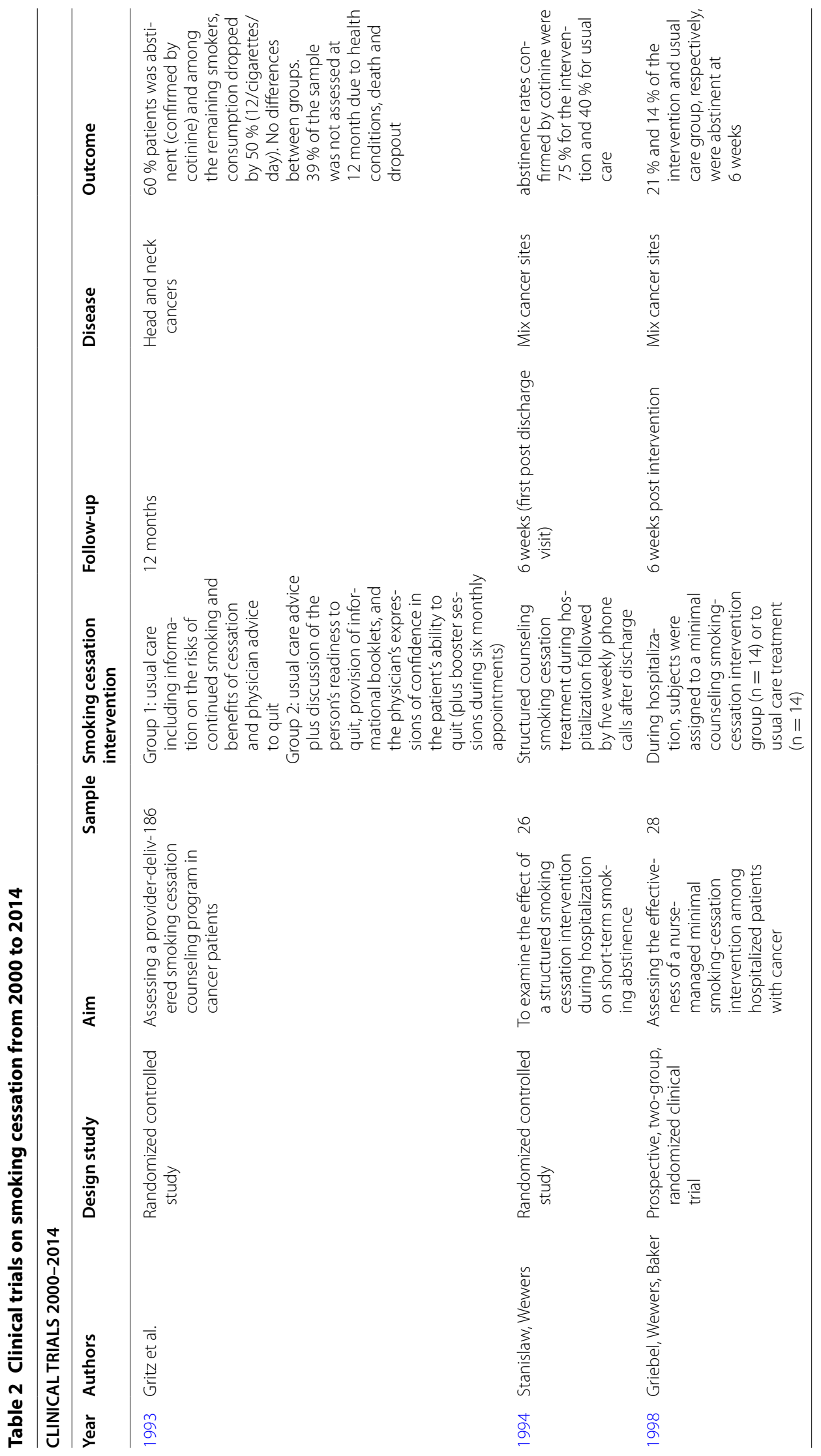




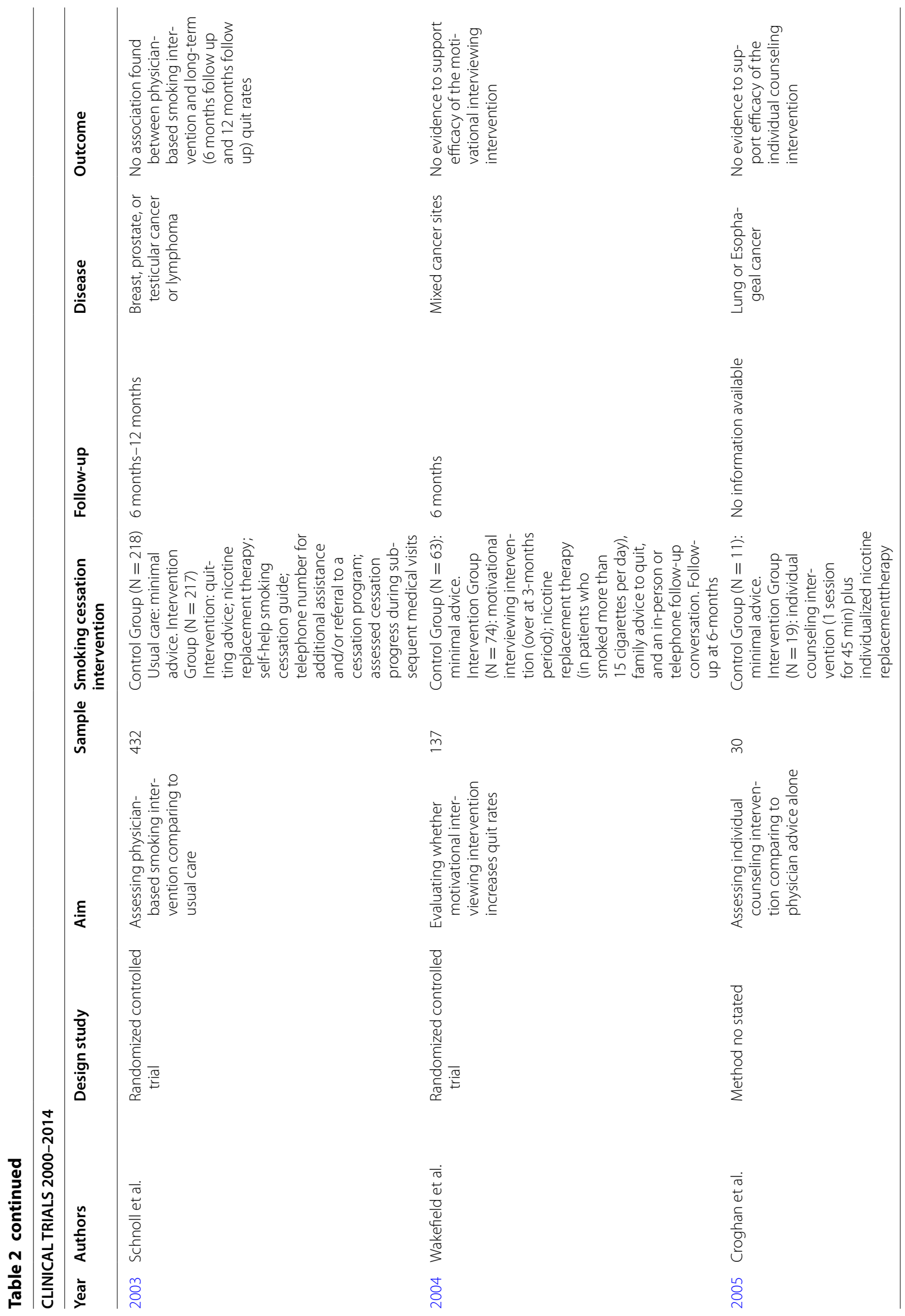




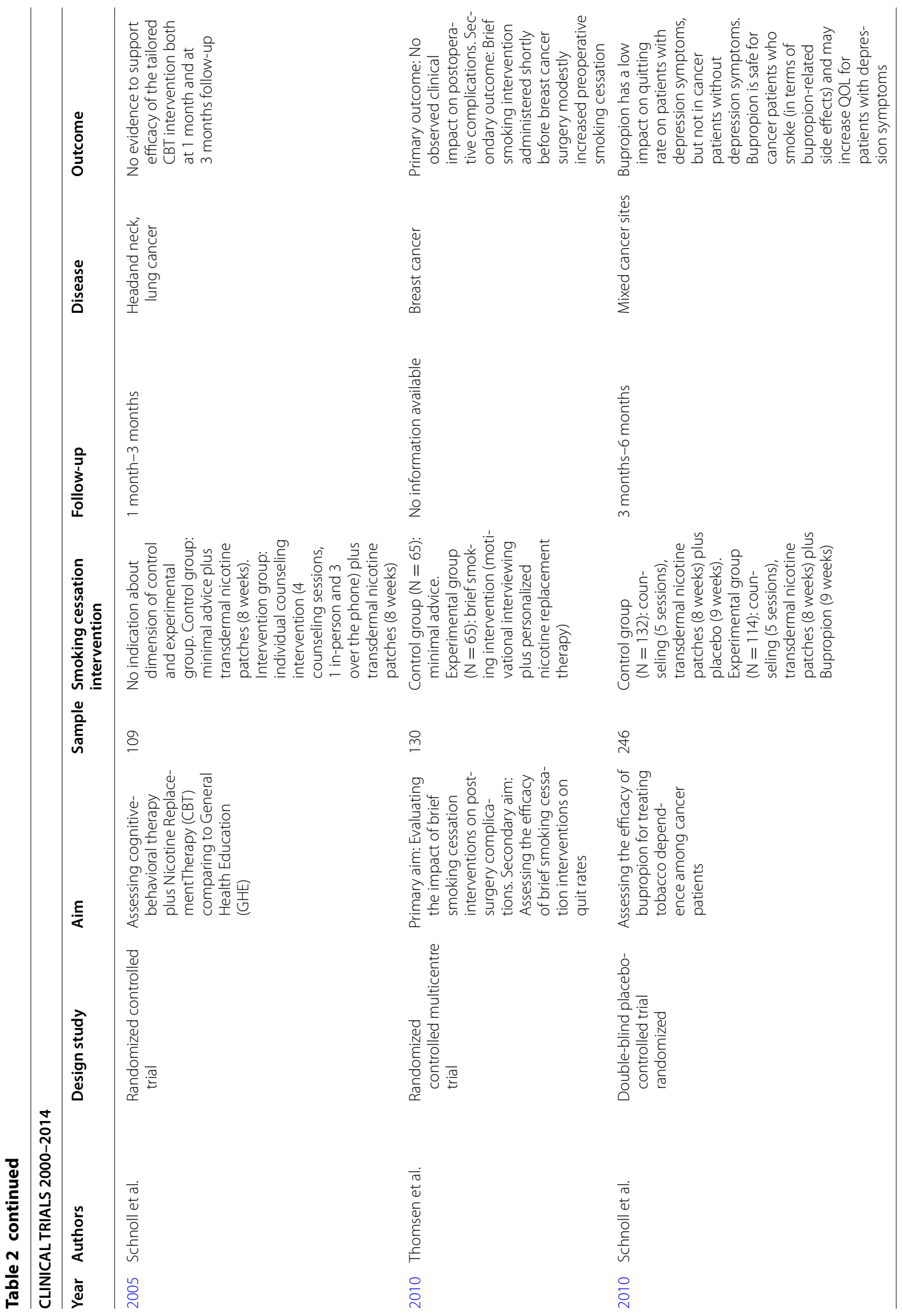




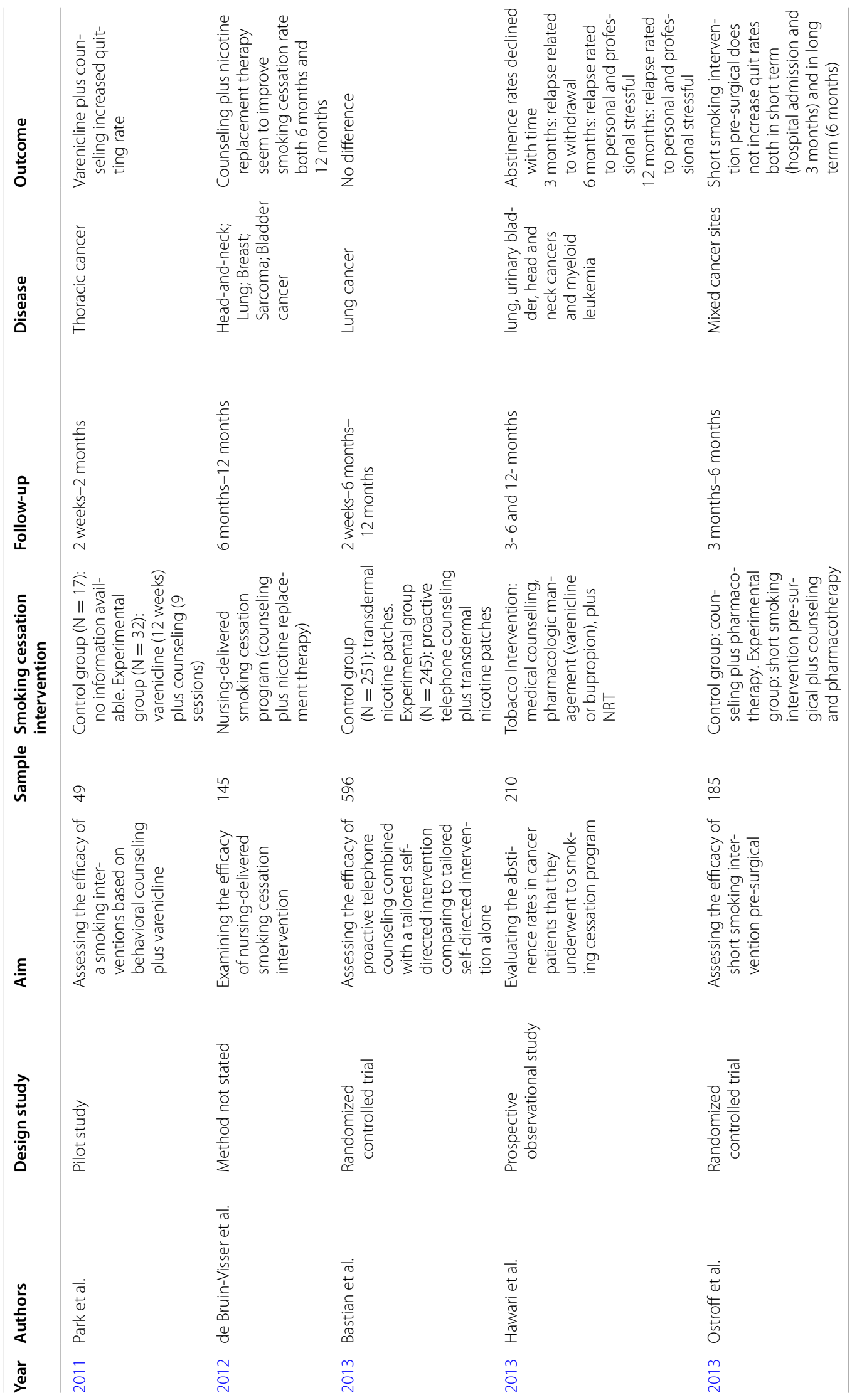




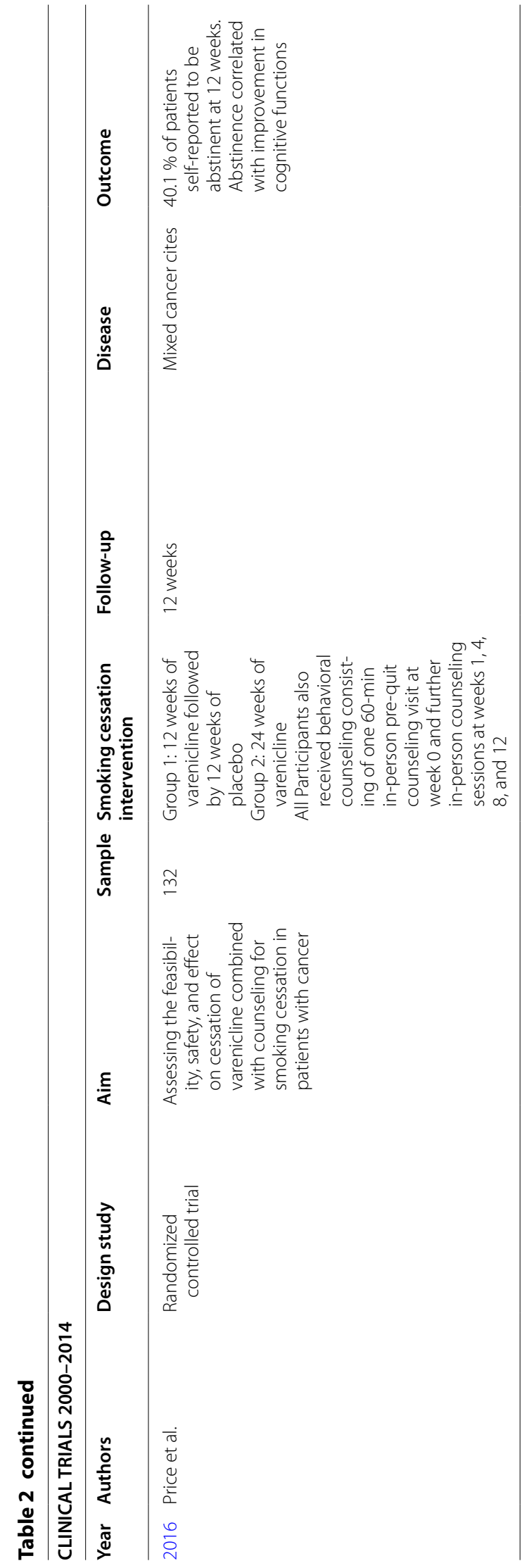


TFCs containing nicotine can be considered a NRT, albeit with specific and distinct characteristics. Firstly, comparing TFCs with traditional NRTs, the former deliver a modest amount of nicotine (Fagerström and Eissenberg 2012). Secondly, TFCs present a better usability and they are more appealing for smokers since they can be used when needed by a well-known modality, i.e. taking a cigarette-like device to the mouth and inhaling. In doing so, smokers not only may react to an immediate need or desire, but they can enact a gesture associated with their previous status (cigarette smokers), thus eliciting positive emotions and satisfying psychological expectations. Thirdly, TFCs may be used ad libitum enabling patients to feel free to control their behavior instead of feeling an under external imposition. For these reasons, it has been suggested that TFCs fit in very well with both the psychological and physiological needs of smokers who want and/or need to stop.

Some clinical trials revealed that e-cigarettes attenuate the craving for cigarettes (Wagener et al. 2012; Bullen et al. 2013). Furthermore, a recent review of the field showed that TFCs may be considered safe, with few adverse events and limited toxicity (Farsalinos and Polosa 2014). In the general population, nicotine TFCs has been showed to be more efficacious in reducing withdrawal symptoms than nicotine-free TFCs (Etter and Bullen 2011). However, also the latter may be considered valid options in oncology settings when supported by counselling, as shown by ongoing studies (Cipolla 2012; Lucchiari et al. 2016). The use of nicotine-free TFCs allow drug-free smoking cessation treatments, and this fact could be particularly interesting for patients undergoing aggressive therapies or at high risk for cardiovascular events. Though some others studies did not find and effect of the use of TFCs in a population of cancer patients (e.g. Borderud et al. 2014; Barton 2015), we argue that only long run longitudinal studies on targeted population and using randomized design will clarify the role of TFCs devices to help patients to quit smoking.

At the time of publishing, there is a clear gap in the knowledge about the feasibility, efficacy and safety of TFCs in oncology settings. In consideration of the lack of evidence, it is not possible to recommend a systematic use of TFCs with cancer patients (Cummings et al. 2014). However, a number of studies are now open on over the world. At our institution, two trials are currently ongoing to analyse how TFCs with and without nicotine might be included in clinical protocols both during cancer treatments and in early diagnosis screening programs.

Lastly, the pharmacological approach to smoking cessation is mainly based on two medications: bupropion and varenicline, both of which are extensively used in clinical practice. Bupropion is an atypical antidepressant that promotes cessation probably by reducing the stimulating effect of neurotransmitters, being an inhibitor of dopamine and norepinephrine reuptake. It counteracts craving and smoke-related withdrawal symptoms (Jorenby et al. 2006). In addition, it counters emotional distress during abstinence, which is a very important characteristic to consider for cancer patients. Indeed, as noted above, cancer patients frequently experience high levels of depression, and smoking interruption can drastically increase this because of psychological and physiological cigarette dependence.

Bupropion has been administered to cancer patients during treatment, and it was found to improve their mood, facilitating the smoking cessation success. In particular, Schnoll et al. (2010) designed a double-blind, placebo-controlled trial ran on a sample of 246 cancer patients (mix cancer sites). In the first arm of the study, patients received 5 counseling session, 8 weeks of NRT and 9 weeks of bupropion. In the second arm, patients received the same treatment of group 1 , but bupropion was substituted by a placebo. While NRT and counseling was found to be effective in non-depressed patients, bupropion showed to be beneficial for those patient who reported depressive symptoms. Benefits were found both for mood and for smoking cessation rate.

Bupropion has other relevant properties, e.g. it reduces post-cessation weight gain (Martinez et al. 2009), and it can be used even with patients with cardiovascular problems. However, the use of bupropion should be avoided for patients receiving active treatments for brain or other central nervous system cancers, and for those patients with a history of seizures, bulimia or anorexia nervosa. Furthermore, the use of this agent must be carefully weighed when dealing those patients receiving chemotherapy with direct CNS effects due to the increased potential for seizure. More research in the safety of bupropion during cancer therapy is warranted, even though no further contraindications are suggested (Klosky et al. 2007).

A further pharmacological treatment for smoking dependence involves the use of varenicline. This is a partial agonist of nicotinic acetylcholine receptor subtype $\alpha_{4} \beta_{2}$, reducing dopamine stimulation. A study by Gonzales et al. (2006) reported that a 12-weeks varenicline-based treatment counters craving, urgency and withdrawal symptoms in healthy smokers. If properly administered, varenicline causes cigarettes to lose their habitual pleasure, favouring the extinction of the smoking habit (Baraldo et al. 2012; Ebbert et al. 2010). This is particularly true for smokers with a low motivation to give up and/or with important nicotine withdrawal symptoms (Nides 2008). In the general population, varenicline is considered the best option to increase the probability 
of success of a smoking cessation program, reaching a $25-30 \%$ of abstinences within the first year (Issa et al. 2013; Mills et al. 2012). However, a study by Hawari et al. on a heterogeneous sample $(n=199)$ of cancer patients (mix cancer sites) failed to find any significant advantage by the use of varenecline in association with NRT at 3 months with respect to NRT alone.

Nausea, abnormal dreams, upper respiratory tract infection and insomnia are the most commonly reported adverse events, and these are generally mild and self-limiting. Although it has been associated with depression, suicidal behaviour and myocardial infarction (depression is actually a relative contra-indication; Brophy 2011), a recent meta-analysis showed that there is no clear evidence that these side-effects are causally related to the drug use (Prochaska and Hilton 2012). Varenicline should be avoided with pregnant, nursing, in patients with renal impairment or patients younger than 18, but generally appears safe in treating tobacco dependence of patients with cancer. Furthermore, the use of varenicline seem to support cognitive functions (Clinical Practice Guidelines in Oncology: Smoking Cessation 2015). In particular, a recent study by Price et al. (2016) on a sample of 132 smokers with a diagnosis of cancer found that varenicline was well tolerated by patients. They designed a two arms randomized study. Patients received or 12 weeks of varenicline followed by 12 weeks of placebo or a full 24 weeks of varenicline. However, at the moment of publication only data about the first 12 weeks of varenicline are available. The pharmacological treatment was combined with five standardized brief smoking cessation counselling sessions. About $40.1 \%$ of smokers stopped after 12 weeks of treatment, a datum comparable with results found in the general population. Side effects symptoms were present (in particular, nausea and sleep problems) but they did not prevent patients to complete the treatment. Furthermore, abstainers at 12 week showed a significant decrease in cognitive deficits. The authors did not report data about longer-term assessment points and the placebo condition. Furthermore, the cancer stage is very heterogeneous (in the $33.3 \%$ is not specified) and many patients $(25.8 \%)$ are in remission. Under this condition is difficult to evaluate the real ability of patient to tolerate the treatment side effects.

The use of vareniclin in oncological setting require more research in order to establish in which context it should be beneficial.

\section{Cognitive behavioral interventions (CBIs)}

Cognitive behavioral interventions (CBIs) are based on a psychological approach to smoking aimed at supporting people in changing their behavior by a cognitive restructuring. Low-intensity or high-intensity interventions may be used. The low-intensity interventions are more frequently used in oncology settings, in screening programs as well as in other clinical settings. They are characterized by self-help tools and the use of so-called minimal advice. Normally, the self-help tools are booklets, brochures, and informative paper-based support materials, although video clips and computer-based tools are also now available. These tools convey general information about the consequences of smoking and the benefits of giving up.

The main advantage of self-help tools is that they target a large population; unfortunately, their effects are generally poor (Lancaster and Stead 2005).

The minimal advice is a short list of recommendations, requiring just some minutes, focused on why it is important to consider to stop smoking and how (and where) it is possible to address the issue, e.g. starting an antismoking program. This approach is particularly useful in a clinical setting, where trust between patients and physicians is already established and where external but affordable resources are available (e.g. an antismoking center).

When meeting a patient, oncologists and/or nurses may merely explain the importance of interruption of smoking in cancer care and the impact on treatment, but they do not directly suggest strategies or therapies (Emmons et al. 2013).

The minimal advice consists of the evaluation of the personal smoking history and a few suggestions. Several studies reported a delay of specific interventions for patients who smoke after the diagnosis, probably due to a "beating the disease" priority. The urgency of the disease focuses the doctor's attention on the assessment and the cure of clinical conditions, while other aspects may go untreated.

The high intensity interventions involves a counseling approach. Behavioral counseling has been defined as a relationship between an expert and a client, focused on behavior to be changed. Normally, each session lasts 15-30 min.

A broadly used tool is the motivational interview aimed to understand the subjects position within the so-called cognitive spiral of change (Prochaska and DiClemente 1983), and to activate motivational drivers. Previous research has stressed that a high motivational level can facilitate smoking cessation and abstinence, while a low motivational level negatively affects the success rate. The motivational level is considered as a benchmark to decide which strategy to opt for.

Behavioral counseling can be used in oncology settings and continued during the follow-up scheduling. Generally speaking, behavioral counseling starts during the hospitalization and should be continued after discharge. 
It has been shown that it increases the giving-up rate after 6 and 12 months (Rigotti et al. 2008) in hospitalized patiens. Another widespread model, very useful in hospital settings, is telephone counseling. Habitually, it is used in combination with traditional (on-site) counseling (Stead et al. 2006). This intervention can be proactive or reactive (Lichtenstein et al. 1996). The proactive approach targets patients already prompted to give up, and then may be used to monitor the ongoing situation over time. Instead, the reactive approach is based on specific needs of patients (Stead et al. 2008). A review on telephone counselling has stressed that it sustains abstinence in the long run (Tzelepis et al. 2011). The smoking cessation counseling should be accompanied by a set of recommendations regarding the need of a generalized lifestyle change (Anderson et al. 2002). This aspect of counseling could be very important in oncology setting, since physical activity may have a positive impact on quality of life and wellbeing (Gill et al. 2013), thus potentially acting as the trigger of a virtuous circle. Health personnel could use their privileged role to encourage changes in this direction and redirect patients to external services after discharge. Generally, speaking counseling may be considered effective in supporting smoking attempts in oncology settings in association with smoking cessation aids (Klemp et al. 2016). For instance, Park et al. (2011) studied the effect of antismoking counselling in association with a pharmacological tobacco treatment (Varenicline) in a sample of 49 cancer patients with a thoracic cancer, showing the positive impact of this combined treatment. In this study, the intervention consisted in a 12-week program (Varenicline and counseling). Patients in the treatment group received a median of 9 counseling sessions structured according the 5 As brief counseling model (Ask, Advise, Assess, Assist, Arrange follow up). Authors report that the prevalence abstinence rate at 12 week follow-up was 40.6 in the intervention group and 14.3 in the control group.

Similar results were obtained by de Bruin-Visser et al. (2012) using a 1-year minimal intervention counseling program delivered by nurses (one visit a week in the first month and one every other month with the endpoint at 12 months). Authors included in their study 145 patients with mix cancer sites and found a positive effect of the counseling, since at 6 months the $40 \%$ of patients had stopped smoking, and $33 \%$ was abstinent at 12 months. During this period, most patients also use some kind of nicotine substitutes ( $83 \%$ ), but authors report no association between abstinence and the use of nicotine replacement products. However, Bastian et al. (2013) failed to find any positive relationships between a telephonebased counseling program and smoking cessation in a large sample of 596 lung cancer patients. In particular, authors compared an at-distance counseling program (6 calls) based on motivational interviewing techniques with tailored self-directed materials $(\mathrm{n}=245)$ and a minimal intervention based only on tailored self-directed materials $(\mathrm{n}=251)$. In both groups nicotine patches was al used if not contraindicated. Their results showed no differences between the two groups, even though in younger patients $(<50)$ the abstinence rate was higher (16 vs. $4 \%$ ) at 2 weeks post-surgery. This study underline once more that lung cancer patients need intensive interventions to stop smoking.

Other studies have tested the efficacy of a strategy based on a brief physician intervention, showing that low intensity intervention have poor power in helping patients quitting attempts. In particular, Schnoll et al. (2003) compared two large groups of patients (mix cancer sites). The intervention group $(n=217)$ received a minimal advise and information about the benefits of quitting and smoking cessation treatment. Furthermore, patients in this group received a self-help smoking cessation guide a telephone line for additional assistance or information. The control group $(n=218)$ received only a minimal advise about smoking by their physician. At 6 months, $14.4 \%$ patients in group 1 and $11.9 \%$ in group 2 had stopped smoking, showing no significant differences between the two arms of the study.

Though the studies we have considered did not directly analyzed the cost-effectiveness of smoking cessation treatment in oncology settings, de Bruin-Visser et al. (2012) suggest to estimate cost-effective analysis for cancer patients using by studies in the general population. In particular, Song et al. (2002) found that NRT for smoking cessation is cost-effective. The results of the decision analyses indicated that, as compared with advice or counseling alone, the incremental cost per life-years saved is about \$1441-\$3455 for NRT, \$920-\$2150 for bupropion, and $\$ 1282-\$ 2836$ for NRT plus bupropion. The cost-effectiveness of adding NRT and bupropion to advice or counseling for smoking cessation is better than many other accepted health care interventions. Hoogendoorn et al. (2010) analyzed the long-term cost-effectiveness in patients with chronic obstructive pulmonary. They reported that pharmacological treatments in combination with intensive counselling was cost saving compared with intensive counselling alone, and that the latter in turn was more effective than minimal intervention.

Finally, Meenan et al. (1998) analyzed the cost-effectiveness of a hospital-based smoking cessation intervention reporting that the cost of the research intervention was \$159 per smoker, and incremental cost per incremental quit was $\$ 3697$. Incremental cost per incremental discounted life-year saved ranged between $\$ 1691$ and $\$ 7444$, much less than most other routine medical procedures. 


\section{Conclusions}

A cancer diagnosis may represent a fundamental teachable moment for smokers, leading them to give up smoking or to significantly reduce daily cigarettes. Most former smokers declare that they decided to quit due to physical issues or the fear of future health consequences of smoking (Gallus et al. 2013). Furthermore, a regression analysis on 15,489 smokers participating in lung cancer screening studies reviled that smoking cessation is strongly associated with screening abnormalities and that efficacious smoking cessation programs should be integrated within screenings (Tammemägi et al. 2014). Despite this evidence, few studies have directly addressed the problem of how to help a patient with cancer to abandon unhealthy habits. Additionally, even though some recommendations exist, no specific and validated protocols are recognized as a valid and shared antismoking approach in oncology settings. As a consequence of this attitude a cancer patient is rarely concretely and systematically supported in a smoking cessation journey (e.g. Nayan et al. 2011; de Bruin-Visser et al. 2012), with the result that though many patients developed a good motivation to stop, few actually remain abstinent in a long run. Thus, the emotional trigger of the diagnosis and the motivational context of the clinical setting succeed only in helping patients to suspend cigarette smoking for a short period (e.g. Land et al. 2011) but not as a sound lifestyle change.

From a psychosocial point of view, the fact that motivation to stop level regresses to its pre-diagnostic level is an expected phenomenon (Slovic et al. 2004). Indeed, emotions have a time-limited effect and their impact on decision-making processes (e.g. whether to attempt quitting or not) rapidly fades after an emotional burden. Emotions must be considered as short-time cognitive modulators, being able to focus attention on risk-related behaviors and the need to avoid them in a specific spatial and temporal context (Pravettoni et al. 2012). Consequently, time matters, since the more time pass between diagnosis and treatments the more the motivation to quit decreases.

Furthermore, in order to help oncology patients to reduce smoking-related risks, it is vital to know the general characteristics of the context in which the emotions arose. If a patient learns in a specific, clinical setting (a surgery and/or oncology department) that smoking is dangerous and that quitting could be a good solution for their future health, this setting will be associated with that emotionally-laden knowledge. Consequently, patients will develop a situated learning that will motivate their choices. However, when a patient goes back home the context will dramatically change, activating previous learning and habits, e.g. smoking while watching TV or after dinner. Here the motivation to quit will rapidly vanish if not adequately supported by prior interventions and adequately sustained by a continuous help, e.g.by a telephone counseling. Actually, in a study on 721 lung cancer survivors, smoking cessation success was found to be negatively associated with smoking exposure at home (Eng et al. 2014).

Consequently, we argue that in order to help patients to give up smoking, the health personnel working in oncology settings should be prepared to offer a complete program aimed at promoting health by integrating new perspectives and attitudes in patients' values system. Cancer centers should promote smoking cessation applying guidelines and doing more research on smokers' needs in order to implement tailored and effective interventions (Mazza et al. 2010; Cataldo et al. 2010).

In particular, even if it is very important to consider the cancer treatment a teachable moment to help a concrete lifestyle change, we claim that emotions should not be used as levers to force their change, but only as initial triggers. Indeed a social-cognitive approach to patients suggests that physicians and nurses should use their position within the clinical setting to drive patients through a sound learning process, instead of causing just a timelimited suspension of a dysfunctional behavior. In particular, a cognitive perspective should be used in order to understand which personal beliefs sustain the smoking behavior, since biased evaluations could prevent patients success in their attempts to quit (Masiero et al. 2015; Pepper et al. 2014). However, to achieve this aim the hospital personnel should be educated by specific training and motivated to adopt the best practices by hospital initiatives.

Overcoming the limits of the classical minimal advice approach, which could be just the initial part of a more complex process, the social-cognitive intervention should be:

- Integrated the smoking cessation treatment should be experienced as an integral part of the cancer management. In particular, nurses could serve this aim by introducing the issues of smoking and smoking cessation and by evaluating the tobacco dependence and the motivation to stop so to address patients to dedicated services.

- Personalized the therapeutic options provided to patients should be compatible with their values, needs and attitudes. Furthermore, it should address a whole lifestyle change.

- Proactive offering patients continuity in treatments, avoiding offering merely on-demand support or suggestions.

- Reactive providing patients dedicated treatments or support when needed, independently of any therapeutic scheme. 
This approach requires a multidisciplinary effort since physicians, nurses and behavior change specialist should work together each having specific roles (Lucchiari et al. 2013). In particular, physicians should introduce the issue of smoking within the general treatment, using the therapeutic alliance to gain the attention of the patient and guide the subsequent cognitive assessment of smokingrelated risks and benefits of quitting. Some studies (e.g. Mazza et al. 2010) have reported the fear of physicians to suggest antismoking programs due to the fragile emotional situation of patients, and the potential to cause distress responses. Nonetheless, an antismoking pathway should not be experienced by patients as a further stressor, and we suggest that health personnel could play a vital role in helping patients to approach the problem in a balanced fashion, to reduce stress and maximize benefits. Since a number of studies on cancer patients demonstrate moderate smoking cessation success following the general principles of evidence-based smoking cessation protocol (Gritz et al. 2014) a targeted and interdisciplinary approach should be adopted using systematic monitoring of patients' needs and behavior in order to sustain long-term abstinence (Hawari et al. 2013). However, when this is not possible, physicians and nurses should act as valuable information carriers, addressing relevant issues and encouraging patients to search for support in external services.

Health personnel should provide detailed information about smoking hazards (both before, during and after cancer) and support patients' motivation to start an attempt to quit (Zwar et al. 2011). This support should be based on a social-cognitive perspective, since any information and/or advice provided should be aimed at breaking down false beliefs and cognitive biases and at reinforcing the emotional, physical and social benefits of the change. Consequently, personnel should be well trained in performing this task and they should be aware of the important role they are playing in the whole process. This mean that physicians and nurses are regarded not only as information bearers, but also as change facilitators, potentially making a great difference in the result (Cooley et al. 2008). Finally, specialized counselors should follow the entire clinical pathway by regular meeting (potentially also at a distance, e.g. by telephone) to provide emotional support, sustain motivation, and approach specific concerns. This should also include behavioral interventions (e.g. helping patients to manage anxiety states, sleep disturbances and the like).

Physicians, nurses and specialists must therefore work in an integrated fashion, able to exchange information, keep track of the patients' history and adequately respond to patients' demands throughout all the oncology treatment. This also means that when patients need help, e.g. in the use of antismoking medications or in following specific procedures, they can easily find practical support, as some studies have shown that patients often fail to continue the antismoking treatment due to practical problems (e.g. McBride and Ostroff 2003). Indeed, a whole and integrated approach will get patients into a protection context, where emotional, behavioral and practical issues are continually monitored and supported. However, the future success of tobacco smoking programs in oncology settings will depend on the level of knowledge education and motivation of health personnel.

\section{Authors' contributions}

$\mathrm{CL}$ and $\mathrm{MM}$ searched for and collected the scientific literature to work under the supervision of GP and, for the oncological and pharmaceutical studies,

AB. All papers were discussed and commented by all authors. The article text was drafted by $\mathrm{CL}$ and MM and then amended by others. All authors read and approved the final manuscript.

\section{Author details}

${ }^{1}$ Department of Philosophy, Università degli Studi di Milano, Milan, Italy. ${ }^{2}$ Department of Oncology and Hemato-Oncology, Università degli Studi di Milano, Milan, Italy. ${ }^{3}$ Applied Research Unit for Cognitive and Psychological Science, European Institute of Oncology, Milan, Italy. ${ }^{4}$ Department of Neurooncology, Fondazione IRCCS Istituto Neurologico C. Besta, Milan, Italy.

\section{Competing interests}

The authors declare that they have no competing interests.

Received: 9 October 2015 Accepted: 8 July 2016

Published online: 20 July 2016

\section{References}

Anderson JE, Jorenby DE, Scott WJ, Fiore MC (2002) Treating tobacco use and dependence an evidence-based clinical practice guideline for tobacco cessation. CHEST J 121(3):932-941

Ark WV, DiNardo LJ, Oliver DS (1997) Factors affecting smoking cessation in patients with head and neck cancer. Laryngoscope 107(7):888-892

Arnett JJ (2000) Optimistic bias in adolescent and adult smokers and nonsmokers. Addict Behav 25(4):625-632

Balmford J, Borland R, Hammond D, Cummings KM (2011) Adherence to and reasons for premature discontinuation of stop-smoking medications: data from the ITC Four-Country Survey. Nicotine Tob Res 13(2):94-102

Baraldo S, Turato G, Saetta M (2012) Pathophysiology of the small airways in chronic obstructive pulmonary disease. Respiration 84(2):89-97

Barton MK (2015) Electronic cigarettes did not help patients with cancer stop smoking. CA Cancer J Clin 65(2):85-86

Bastian LA, Fish LJ, Peterson BL, Biddle AK, Garst J, Lyna P, McBride CM (2013) Assessment of the impact of adjunctive proactive telephone counseling to promote smoking cessation among lung cancer patients' social networks. Am J Health Promot 27(3):181-190

Blalock JA, Lam C, Minnix JA, Karam-Hage M, Gritz ER, Robinson JD, Cinciripini PM (2011) The effect of mood, anxiety, and alcohol use disorders on smoking cessation in cancer patients. J Cogn Psychother 25(1):82-96

Bock BC, Becker B, Monteiro R, Partridge R, Fisher S, Spencer J (2001) Physician intervention and patient risk perception among smokers with acute respiratory illness in the emergency department. Prev Med 32:175-181

Borderud SP, Li Y, Burkhalter JE, Sheffer CE, Ostroff JS (2014) Electronic cigarette use among patients with cancer: characteristics of electronic cigarette users and their smoking cessation outcomes. Cancer 120:3527-3535. doi:10.1002/cncr.28811

Borrelli B, Hayes RB, Dunsiger S, Fava JL (2010) Risk perception and smoking behavior in medically ill smokers: a prospective study. Addiction 105(6):1100-1108 
Brophy JM (2011) ACP journal club. Review: varenicline increases the risk of serious adverse cardiovascular events in tobacco users. Ann Intern Med 155:JC4-JC5

Bullen C, Howe C, Laugesen M et al (2013) Electronic cigarettes for smoking cessation: a randomized controlled trial. Lancet S1040-6736(13):61842-61845

Burris JL, Studts JL, DeRosa AP, Ostroff JS (2015) Systematic review of tobacco use after lung or head/neck cancer diagnosis: results and recommendations for future research. Cancer Epidemiol Biomark Prev 24(10):1450-1461

Cataldo JK, Dubey S, Prochaska JJ (2010) Smoking cessation: an integral part of lung cancer treatment. Oncology 78(5-6):289-301

Champassak SL, Goggin K, Finocchario-Kessler S, Farris M, Ehtesham M, Schoor R, Catley D (2014) A qualitative assessment of provider perspectives on smoking cessation counseling. J Eval Clin Pract 20(3):281-287

Chang G, John Orav E, McNamara T, Tong MY, Antin JH (2004) Depression, cigarette smoking, and hematopoietic stem cell transplantation outcome. Cancer 101(4):782-789

Chapple A, Ziebland S, McPherson A (2004) Stigma, shame, and blame experienced by patients with lung cancer: a qualitative study. BMJ (International Edition) 328(7454):1470-1473

Cipolla C (2012) Early smoking reduction or cessation by means of no nicotine electronic cigarette added to standard, ClinicalTrials.gov Identifier: NCT01733706

Cooley ME, Sipples RL, Murphy M, Sarna L (2008) Smoking cessation and lung cancer: oncology nurses can make a difference. Semin Oncol Nurs 24(1):16-26

Cooley ME, Sarna L, Kotlerman J, Lukanich JM, Jaklitsch M, Green SB, Bueno $R$ (2009) Smoking cessation is challenging even for patients recovering from lung cancer surgery with curative intent. Lung Cancer 66(2):218-225

Croghan G, Croghan I, Frost M, Sloan JA, Novotny PJ, Nelson MA (2005) Smoking cessation interventions and post-operative outcomes in esophageal and lung cancer patients. Society for research on nicotine and tobacco 11 th annual meeting, 20-23

Cropley M, Theadom A, Pravettoni G, Webb G (2008) The effectiveness of smoking cessation interventions prior to surgery: a systematic review. Nicotine Tob Res 10(3):407-412

Cummings KM, Dresler CM, Field JK, Fox J, Gritz ER, Hanna NH, Zhou C (2014) E-cigarettes and cancer patients. J Thorac Oncol 9(4):438-441

Daniel M, Keefe FJ, Lyna P, Peterson B, Garst J, Kelley M, Bastian LA (2009) Persistent smoking after a diagnosis of lung cancer is associated with higher reported pain levels. J Pain 10(3):323-328

de Bruin-Visser JC, Ackerstaff AH, Rehorst H, Retèl VP, Hilgers FJM (2012) Integration of a smoking cessation program in the treatment protocol for patients with head and neck and lung cancer. Eur Arch Otorhinolaryngol 269(2):659-665

Dresler CM, Bailey M, Roper CR, Patterson GA, Cooper JD (1996) Smoking cessation and lung cancer resection. Chest 110:1199-1202

Duffy SA, Louzon SA, Gritz ER (2012) Why do cancer patients smoke and what can providers do about it? Community Oncol 9(11):344

Ebbert JO, Wyatt KD, Hays JT, Klee EW, Hurt RD (2010) Varenicline for smoking cessation: efficacy, safety, and treatment recommendations. Patient Prefer Adherence 4:355

Ehlers S, Bronars C (2012) Effect of smoking on the outcomes of cancer patients after hematopoietic stem cell transplantation. Stem Cells Cancer Stem Cells 8:337-343

Ehlers SL, Gastineau DA, Patten CA, Decker PA, Rausch SM, Cerhan JR et al (2011) The impact of smoking on outcomes among patients undergoing hematopoietic SCT for the treatment of acute leukemia. Bone Marrow Transplant 46:285-290

Elfeddali I, Bolman C, Candel MJJ, Wiers RW, De Vries H (2012) The role of selfefficacy, recovery self-efficacy, and preparatory planning in predicting short-term smoking relapse. Br J Health Psychol 17(1):185-201

Emmons KM, Sprunck-Harrild K, Puleo E, de Moor J (2013) Provider advice about smoking cessation and pharmacotherapy among cancer survivors who smoke: practice guidelines are not translating. Transl Behav Med 3(2):211-217

Eng L, Su J, Qiu X, Palepu PR, Hon H, Fadhel E, Liu G (2014) Second-hand smoke as a predictor of smoking cessation among lung cancer survivors. J Clin Oncol 32(6):564-570
Etter JF, Bullen C (2011) Electronic cigarette: users profile, utilization, satisfaction and perceived efficacy. Addiction 106(11):2017-2028

Fagerström K, Eissenberg T (2012) Dependence on tobacco and nicotine products: a case for product-specific assessment. Nicotine Tob Res 14(11):1382-1390

Farsalinos KE, Polosa R (2014) Safety evaluation and risk assessment of electronic cigarettes as tobacco cigarette substitutes: a systematic review. Ther Adv Drug Saf 5(2):67-86

Ferguson SG, Gitchell JG, Shiffman S, Sembower MA, Rohay JM, Allen J (2011) Providing accurate safety information may increase a smoker's willingness to use nicotine replacement therapy as part of a quit attempt. Addict Behav 36(7):713-716

Field M, Munafò MR, Franken IH (2009) A meta-analytic investigation of the relationship between attentional bias and subjective craving in substance abuse. Psychol Bull 135(4):589

Fiore MC, Bailey WC, Cohen SJ et al (2000) Treating tobacco use and dependence. A clinical practice guideline. US Department of Health and Human Services: AHRQ publication No. 00-0032, Rockville

Fiore M, Jean CR, Baker TB, Bailey WC, Benowitz NL, Curry SJ, Wers L (2008) Treating tobacco use and dependence: update 2008. U.S. Department of Health and Human Services, Public Health Service, Public Health Service, Rockville

Gallus S, Muttarak R, Franchi M, Pacifici R, Colombo P, Boffetta P, La Vecchia C (2013) Why do smokers quit? Eur J Cancer Prev 22(1):96-101

Gandini S, Botteri E, lodice S, Boniol M, Lowenfels AB, Maisonneuve P, Boyle P (2008) Tobacco smoking and cancer: a meta-analysis. Int J Cancer 122(1):155-164

Garces YI, Schroeder DR, Nirelli LM, Croghan GA, Croghan IT, Foote RL, Hurt RD (2004) Tobacco use outcomes among patients with head and neck carcinoma treated for nicotine dependence. Cancer 101(1):116-124

Gill DL et al (2013) Physical activity and quality of life. J Prev Med Public Health 46(Suppl 1):S28-S34

Gonzales D, Rennard SI, Nides M, Oncken C, Azoulay S, Billing CB, Reeves KR (2006) Varenicline, an $a 4 \beta 2$ nicotinic acetylcholine receptor partial agonist, vs sustained-release bupropion and placebo for smoking cessation. JAMA J Am Med Assoc 296(1):47-55

Griebel B, Wewers ME, Baker CA (1998) The effectiveness of a nurse-managed minimal smoking-cessation intervention among hospitalized patients with cancer. In: Oncology nursing forum, vol 25, no 5, pp 897-902

Gritz ER (1991) Smoking and smoking cessation in cancer patients. Br J Addict 86(5):549-554

Gritz ER, Demark-Wahnefried W (2009) Health behaviors influence cancer survival. J Clin Oncol 27(12):1930-1932

Gritz ER, Carr CR, Rapkin D, Abemayor E, Chang $\amalg$, Wong WK, Chonkich G (1993) Predictors of long-term smoking cessation in head and neck cancer patients. Cancer Epidemiol Biomark Prev 2(3):261-270

Gritz ER, Dresler C, Sarna L (2005) Smoking, the missing drug interaction in clinical trials: ignoring the obvious. Cancer Epidemiol Biomark Prev 14(10):2287-2293

Gritz ER, Toll BA, Warren GW (2014) Tobacco use in the oncology setting: advancing clinical practice and research. Cancer Epidemiol Biomark Prev 23(1):3-9

Hawari Fl, Obeidat NA, Ayub HS, Sattam S, Dawahrah SFH (2013) Smoking cessation treatment and outcomes in medium to heavy cigarette smokers being treated for cancer in Jordan. Asian Pac J Cancer Prev 14(11):6875-6881

Hoogendoorn M, Feenstra TL, Hoogenveen RT, Rutten-van Molken MP (2010) Long-term effectiveness and cost-effectiveness of smoking cessation interventions in patients with chronic obstructive pulmonary disease. Thorax 65(8):711-718

Hurt RD, Ebbert JO, Hays JT, McFadden DD (2009) Treating tobacco dependence in a medical setting. CA Cancer J Clin 59(5):314-326

Husten CG (2009) How should we define light or intermittent smoking? Does it matter? Nicot Tob Res ntp010

Issa JS, Abe TO, Moura S, Santos PC, Pereira AC (2013) Effectiveness of coadministration of varenicline, bupropion, and serotonin reuptake inhibitors in a smoking cessation program in the real-life setting. Nicotine Tob Res 15(6):1146-1150

Jorenby DE, Hays JT, Rigotti NA, Azoulay S, Watsky EJ, Williams KE, Reeves KR (2006) Efficacy of varenicline, an a $4 \beta 2$ nicotinic acetylcholine receptor 
partial agonist, vs placebo or sustained-release bupropion for smoking cessation. JAMA J Am Med Assoc 296(1):56-63

Khullar D, Schroeder SA, Maa J (2013) Helping smokers quit around the time of surgery. JAMA 309(10):993-994

Klemp I, Steffenssen M, Bakholdt V, Thygesen T, Sørensen JA (2016) Counseling is effective for smoking cessation in head and neck cancer patients - a systematic review and meta-analysis. J Oral Maxillofac Surg

Klosky JL, Tyc VL, Garces-Webb DM, Buscemi J, Klesges RC, Hudson MM (2007) Emerging issues in smoking among adolescent and adult cancer survivors. Cancer 110(11):2408-2419

Krebber AMH, Buffart LM, Kleijn G, Riepma IC, Bree R, Leemans CR, Verdonckde Leeuw IM (2014) Prevalence of depression in cancer patients: a meta-analysis of diagnostic interviews and self-report instruments. Psycho Oncol 23(2):121-130

Lancaster T, Stead LF (2005) Self-help interventions for smoking cessation. Cochrane Database Syst Rev 3:3

Land SR, Cronin WM, Wickerham DL, Costantino JP, Christian NJ, Klein WM, Ganz PA (2011) Cigarette smoking, obesity, physical activity, and alcohol use as predictors of chemoprevention adherence in the national surgical adjuvant breast and bowel project p-1 breast cancer prevention trial. Cancer Prev Res 4(9):1393-1400

Lichtenstein E, Glasgow RE, Lando HA, Ossip-Klein DJ, Boles SM (1996) Telephone counseling for smoking cessation: rationales and meta-analytic review of evidence. Health Educ Res 11(2):243-257

Lucchiari C, Masiero M, Pravettoni G (2013) Cognitive approach to nutrition in a patient-centered approach: implementing tailored nutrition advice for oncology patients. Eur J Person Centered Healthc 1 (1):265-273

Lucchiari C, Masiero M, Veronesi G, Maisonneuve P, Spina S, Jemos C, Omodeo Salè E, Pravettoni G (2016) Benefits of E-cigarettes among heavy smokers undergoing a lung cancer screening program: randomized controlled trial protocol. JMIR Res Prot 5(1):e21. doi:10.2196/resprot.4805

Marks DI, Ballen K, Logan BR, Wang Z, Sobocinski KA, Bacigalupo A et al (2009) The effect of smoking on allogeneic transplant outcomes. Biol Blood Marrow Transpl 15:1277-1287

Martinez E, Tatum KL, Weber DM, Kuzla N, Pendley A, Campbell K, Schnoll RA (2009) Issues related to implementing a smoking cessation clinical trial for cancer patients. Cancer Causes Control 20(1):97-104

Masiero M, Lucchiari C, Pravettoni G (2015) Personal fable: optimistic bias in cigarette smokers. Int J High Risk Behav Addict 4(1):e20939

May S, West R (2000) Do social support interventions ("buddy systems") aid smoking cessation? A review. Tob Control 9(4):415-422

Mazza R, Lina M, Boffi R, Invernizzi G, De Marco C, Pierotti M (2010) Taking care of smoker cancer patients: a review and some recommendations. Ann Oncol mdp599

McBride CM, Ostroff JS (2003) Teachable moments for promoting smoking cessation: the context of cancer care and survivorship. Cancer Control 10(4):325-333

McClave AK, Dube SR, Strine TW, Kroenke K, Caraballo RS, Mokdad AH (2009) Associations between smoking cessation and anxiety and depression among US adults. Addict Behav 34(6):491-497

Meenan RT, Stevens VJ, Hornbrook MC, La Chance P, Glasgow RE, Hollis JF, Lichtenstein E, Vogt TM (1998) Cost-effectiveness of a hospital-based smoking cessation intervention. Med Care 36(5):670-678

Milbury K, Badr H, Carmack CL (2012) The role of blame in the psychosocial adjustment of couples coping with lung cancer. Ann Behav Med 44(3):331-340

Mills EJ, Wu P, Lockhart I, Thorlund K, Puhan M, Ebbert JO (2012) Comparisons of high-dose and combination nicotine replacement therapy, varenicline, and bupropion for smoking cessation: a systematic review and multiple treatment meta-analysis. Ann Intern Med 44:588-597

Morgan G, Schnoll RA, Alfano CM, Evans SE, Goldstein A, Ostroff J, Cox LS (2011) National cancer institute conference on treating tobacco dependence at cancer centers. J Oncol Pract 7(3):178-182

Nayan S, Gupta MK, Sommer DD (2011) Evaluating smoking cessation interventions and cessation rates in cancer patients: a systematic review and meta-analysis. ISRN Oncol

NCCN (2015) Clinical practice guidelines in oncology: smoking cessation, version I. J Natl Compr Cancer Netw 13(4):xliv

Nides M (2008) Update on pharmacologic options for smoking cessation treatment. Am J Med 121(4):S20-S31
Ostroff JS, Burkhalter JE, Cinciripini PM, Li Y, Shiyko MP, Lam CY, Manna R (2013) Randomized trial of a presurgical scheduled reduced smoking intervention for patients newly diagnosed with cancer

Park EW, Schultz JK, Tudiver F, Campbell T, Becker L (2004) Enhancing partner support to improve smoking cessation. Cochrane Database Syst Rev 3

Park ER, Japuntich S, Temel J, Lanuti M, Pandiscio J, Hilgenberg J, Rigotti NA (2011) A smoking cessation intervention for thoracic surgery and oncology clinics: a pilot trial. J Thorac Oncol 6(6):1059

Pepper JK, Emery SL, Ribisl KM, Rini CM, Brewer NT (2014) How risky is it to use e-cigarettes? Smokers' beliefs about their health risks from using novel and traditional tobacco products. J Behav Med 1-9

Pravettoni G, Masiero M, Gorini A, Lucchiari C (2012) Food choice and smoking behavior: a crossroads in youth. In: Food consumption, communication, life styles and fashion/[a cura di] M. Bustreo, V. Russo.-Milano Qanat 274-290

Price S, Hitsman B, Veluz-Wilkins A, Blazekovic S, Brubaker TR, Leone F, Patel $J$ (2016) The use of varenicline to treat nicotine dependence among patients with cancer. Psycho Oncol

Prochaska JO, DiClemente CC (1983) Stages and processes of self-change of smoking: toward an integrative model of change. J Consult Clin Psychol 51(3):390

Prochaska JJ, Hilton JF (2012). Risk of cardiovascular serious adverse events associated with varenicline use for tobacco cessation: systematic review and meta-analysis. BMJ Br Med J 344

Rigotti NA, Munafo MR, Stead LF (2008) Smoking cessation interventions for hospitalized smokers: a systematic review. Arch Intern Med 168(18):1950-1960

Sanderson-Cox L, Sloan JA, Patten CA et al (2002) Smoking behavior of 226 patients with diagnosis of stage IIIA/IIIB non-small cell lung cancer. Psychooncology 11:472-478

Schnoll RA, Malstrom M, James C, Rothman RL, Miller SM, Ridge JA, Goldberg M (2002) Correlates of tobacco use among smokers and recent quitters diagnosed with cancer. Patient Educ Couns 46(2):137-145

Schnoll RA, Zhang B, Rue M, Krook JE, Spears WT, Marcus AC, Engstrom PF (2003) Brief physician-initiated quit-smoking strategies for clinical oncology settings: a trial coordinated by the Eastern Cooperative Oncology Group. J Clin Oncol 21(2):355-365

Schnoll RA, Rothman RL, Newman H, Lerman C, Miller SM, Movsas B, Cheng $J$ (2004) Characteristics of cancer patients entering a smoking cessation program and correlates of quit motivation: implications for the development of tobacco control programs for cancer patients. Psycho Oncol 13(5):346-358

Schnoll RA, Rothman RL, Wielt DB, Pedri H, Wang H, Babb J, Lerman C (2005) A randomized pilot study of cognitive-behavioral therapy versus basic health education for smoking cessation among cancer patients. Ann Behav Med 30(1):1-11

Schnoll RA, Martinez E, Tatum KL, Weber DM, Kuzla N, Glass M, Leone F (2010) A bupropion smoking cessation clinical trial for cancer patients. Cancer Causes Control 21(6):811-820

Shin DW, Park JH, Kim SY, Park EW, Yang HK, Ahn E, Seo HG (2014) Guilt, censure, and concealment of active smoking status among cancer patients and family members after diagnosis: a nationwide study. Psycho Oncol 23(5):585-591

Slovic P, Finucane ML, Peters E, MacGregor DG (2004) Risk as analysis and risk as feelings: some thoughts about affect, reason, risk, and rationality. Risk Anal 24(2):311-322

Song F, Raftery J, Aveyard P, Hyde C, Barton P, Woolacott N (2002) Costeffectiveness of pharmacological interventions for smoking cessation: a literature review and a decision analytic analysis. Med Decis Making 22(5 suppl):S26-S37

Spek V, Lemmens F, Chatrou M, van Kempen S, Pouwer F, Pop V (2013) Development of a smoking abstinence self-efficacy questionnaire. Int J Behav Med 1-6

Stanislaw AE, Wewers ME (1994) A smoking cessation intervention with hospitalized surgical cancer patients: a pilot study. Cancer Nurs 17(2):81-86

Stead LF, Perera R, Lancaster T (2006) Telephone counselling for smoking cessation. Cochrane Database Syst Rev 3:CD002850

Stead LF, Perera R, Bullen C, Mant D, Lancaster T (2008) Nicotine replacement therapy for smoking cessation. Cochrane Database Syst Rev 1:1 
Tammemägi MC, Berg CD, Riley TL, Cunningham CR, Taylor KL (2014) Impact of lung cancer screening results on smoking cessation. J Natl Cancer Inst 106(6):dju084

Thomsen T, Villebro N, Møller AM (2010) Interventions for preoperative smoking cessation. Cochrane Database Syst Rev 7:CD002294

Thomsen T, Tønnesen H, Okholm M, Kroman N, Maibom A, Sauerberg ML, Møller AM (2010b) Brief smoking cessation intervention in relation to breast cancer surgery: a randomized controlled trial. Nicotine Tob Res 12(11):1118-1124

Toll BA, Brandon TH, Gritz ER et al (2013) Assessing tobacco use by cancer patients and facilitating cessation: an American Association for Cancer Research policy statement. Clin Cancer Res 19:1941-1948

Tzelepis F, Paul CL, Wiggers J, Walsh RA, Knight J, Duncan SL, Daly J (2011) A randomized controlled trial of proactive telephone counseling on coldcalled smokers' cessation rates. Tob Control 20(1):40-46

Vaidya V, Hufstader-Gabriel M, Gangan N, Shah S, Bechtol R (2014) Utilization of smoking-cessation pharmacotherapy among chronic obstructive pulmonary disease (COPD) and lung cancer patients. Curr Med Res Opin 30(6):1043-1050

Videtic GM, Stitt LW, Dar AR, Kocha WI, Tomiak AT, Truong PT, Edward WY (2003) Continued cigarette smoking by patients receiving concurrent chemoradiotherapy for limited-stage small-cell lung cancer is associated with decreased survival. J Clin Oncol 21 (8):1544-1549

Wagener TL, Siegel M, Borrelli B (2012) Electronic cigarettes: achieving a balanced perspective. Addiction 107(9):1545-1548

Wakefield M, Olver I, Whitford H, Rosenfeld E (2004) Motivational interviewing as a smoking cessation intervention for patients with cancer: randomized controlled trial. Nurs Res 53(6):396-405

Walker MS, Larsen RJ, Zona DM, Govindan R, Fisher EB (2004) Smoking urges and relapse among lung cancer patients: findings from a preliminary retrospective study. Prev Med 39(3):449-457

Walker MS, Vidrine DJ, Gritz ER, Larsen RJ, Yan Y, Govindan R, Fisher EB (2006) Smoking relapse during the first year after treatment for earlystage non-small-cell lung cancer. Cancer Epidemiol Biomark Prev 15(12):2370-2377
Waller LL, Weaver KE, Petty WJ, Miller AA (2010) Effects of continued tobacco use during treatment of lung cancer. Expert Rev Anticancer Ther 10(10):1569-1575

Warren GW, Marshall JR, Cummings KM, Toll B, Gritz ER, Hutson A, Dibaj S, Herbst R, Dresler C (2013) Practice patterns and perceptions of thoracic oncology providers on tobacco use and cessation in cancer patients. J Thorac Oncol 8(5):543

Weaver KE, Danhauer SC, Tooze JA, Blackstock AW, Spangler J, Thomas L, Sutfin EL (2012) Smoking cessation counseling beliefs and behaviors of outpatient oncology providers. Oncologist 17(3):455-462

Weinstein ND (1989) Optimistic biases about personal risks. Science 246(4935):1232-1233

Weinstein ND, Marcus SE, Moser RP (2005) Smokers' unrealistic optimism about their risk. Tob Control 14(1):55-59

Westmaas JL, Newton CC, Stevens VL, Flanders WD, Gapstur SM, Jacobs EJ (2015) Does a recent cancer diagnosis predict smoking cessation? an analysis from a large prospective US cohort. J Clin Oncol 33(15):1647-1652

WHO (2011) Report on the global tobacco epidemic: warning about the dangers of tobacco

Zevallos JP, Mallen MJ, Lam CY, Karam-Hage M, Blalock J, Wetter DW, Cinciripini PM (2009) Complications of radiotherapy in laryngopharyngeal cancer. Cancer 115(19):4636-4644

Zhang J, Kamdar O, Le W, Rosen GD, Upadhyay D (2009) Nicotine induces resistance to chemotherapy by modulating mitochondrial signaling in lung cancer. Am J Respir Cell Mol Biol 40(2):135

Zwar N, Richmond R, Borland R, Peters M, Litt J, Bell J, Caldwell B, Ferretter I (2011) Supporting smoking cessation: a guide for health professionals. The Royal Australian College of General Practitioners, Melbourne

\section{Submit your manuscript to a SpringerOpen ${ }^{\circ}$ journal and benefit from:}

- Convenient online submission

- Rigorous peer review

- Immediate publication on acceptance

- Open access: articles freely available online

- High visibility within the field

- Retaining the copyright to your article

Submit your next manuscript at $\boldsymbol{\nabla}$ springeropen.com 